\title{
LETTER
}

\section{Strength contrast between plagioclase and olivine at water-rich Moho depths}

\author{
Shintaro AzUma ${ }^{*}$, Ikuo Katayama ${ }^{*}$, Ken-ichi HiRauchi and Shigeru Yamashita** \\ "Department of Earth and Planetary Systems Science, Hiroshima University, \\ Higashi-Hiroshima, Hiroshima 739-8526, Japan \\ **Institute for Study of the Earth's interior, Okayama University, Tottori 682-0193, Japan
}

\begin{abstract}
Strength contrast between plagioclase and olivine was tested utilizing two-layer deformation experiments under hydrous conditions at the pressure and temperature corresponding to the Moho ( $P=1.0 \mathrm{GPa}$ and $T=400-800$ ${ }^{\circ} \mathrm{C}$ ). Deformation microstructures characterized by lattice-preferred orientation and dislocation density indicate that both minerals were plastically deformed via dislocation-controlled creep. Our experimental results show that olivine is weaker than plagioclase at $T=400^{\circ} \mathrm{C}$, whereas plagioclase is weaker than olivine at $T=800^{\circ} \mathrm{C}$. Consequently, strength contrast between plagioclase and olivine is sensitive to temperature, and olivine may be weaker than plagioclase, or display almost no difference in strength between these materials under the wet continental Moho. This suggests that the "crème brulee" model, in which the upper mantle is weak and the strength is limited to the crust, is expected as a rheological layer model of the water-rich Moho conditions.
\end{abstract}

Keywords: Strength contrast, Olivine, Plagioclase, Strength profile, Moho, Flow-law

\section{INTRODUCTION}

The strength profile of the continental lithosphere is the primary control on seismogenic layering and coupling between the crust and mantle. Physical properties including temperature, pressure, stress, and the chemical layering between crust and mantle result in a strong rheological layering in the Earth's interior (Burgmann and Dresen, 2008). Previous deformation experiments have shown that a brittle-ductile transition occurs in the lithosphere, implying that deformation mechanisms could be changed with increasing depths (e.g., Kohlstedt et al., 1995). Two different models regarding the strength profile have been proposed; (1) the "jelly sandwich" model and (2) the "crème brulee" model. The first model is composed of a weak middle and lower crust that are sandwiched between the strong upper crust and upper mantle (e.g., Chen and Molnar, 1983). The second model is that the upper mantle is significantly weak, and consequently the region for viscous deformation continues to the mantle depths (Jackson, 2002; Burov and Watts, 2006). These two models of the strength profile of the continental lithosphere are inferred by extrapolating frictional behavior and viscous flow law

doi:10.2465/jmps.100618b

S. Azuma, m094785@hiroshima-u.ac.jp Corresponding author

I. Katayama, katayama@hiroshima-u.ac.jp of each material to temperature and pressure corresponding to the Moho depths. Although the power-law relation was commonly applied for the viscous flow law, which was constrained by high temperature experiments, the power-law breakdown might occur at temperatures as low as the Moho depths, and deformation mechanisms could be changed to the Peierls mechanism (Tsenn and Carter, 1987). In this study, we performed experiments to determine the relative strength between plagioclase and olivine at the Moho conditions without any extrapolation of flow law, and discussed which model is suitable to make the strength profile of the continental lithosphere.

\section{EXPERIMENTAL PROCEDURE}

\section{Starting materials}

Crustal materials consist predominantly of plagioclase, which largely controls deformation of the crust, whereas deformation of the upper mantle is largely controlled by olivine (Burgmann and Dresen, 2008). We prepared hotpressed starting materials of each mineral. Firstly, inclusion-free crystals of plagioclase $\left(\mathrm{An}_{66} \mathrm{Ab}_{44}\right)$ and olivine $\left(\mathrm{Fo}_{90} \mathrm{Fa}_{10}\right)$ were carefully selected and crushed using a vibrational mill. Powders of plagioclase and olivine were then cold pressed separately at $P \sim 60 \mathrm{MPa}$ with addition- 
al distilled water $(\sim 50 \mu 1)$. These materials were annealed at $P=196 \mathrm{MPa}$ and $T=1100-1250^{\circ} \mathrm{C}$ for $\sim 4$ hour by HIP (gas-medium apparatus) in Institute for Study of the Earth's interior, Okayama University. The hot-pressed samples show nearly random orientation, and the average grain size of plagioclase is $\sim 15 \mu \mathrm{m}$ and that of olivine is $\sim 20 \mu \mathrm{m}$. We measured water contents of the hot-pressed samples using Fourier-transform infrared (FTIR) spectroscopy. Water contents are $\sim 400 \mathrm{ppm} \mathrm{H} / \mathrm{Si}$ for olivine and $\sim 400 \mathrm{ppm} \mathrm{H/Si}$ for plagioclase, which are nearly saturated values under these conditions (Kohlstedt et al., 1996; Rybacki et al., 2006). After deformation experiments, water contents of the recovered samples were measured and showed only minor changes $\left(\mathrm{C}_{\mathrm{OH}} \sim 350\right.$ ppm H/Si).

\section{Deformation experiments}

Shear deformation experiments were performed using a modified Griggs-type solid-medium apparatus at $P=1$ $\mathrm{GPa}, T=400-800^{\circ} \mathrm{C}$, and a constant displacement rate of $500 \mu \mathrm{m} /$ hour. Thin slices of plagioclase and olivine samples $(0.3-0.45 \mathrm{~mm}$ thick each) were sandwiched together between alumina pistons in a simple shear geometry (Fig. 1). Pressure was first raised to $0.4 \mathrm{GPa}$, and temperature was increased at a rate of $\sim 15{ }^{\circ} \mathrm{C} / \mathrm{min}$ to $400{ }^{\circ} \mathrm{C}$. The

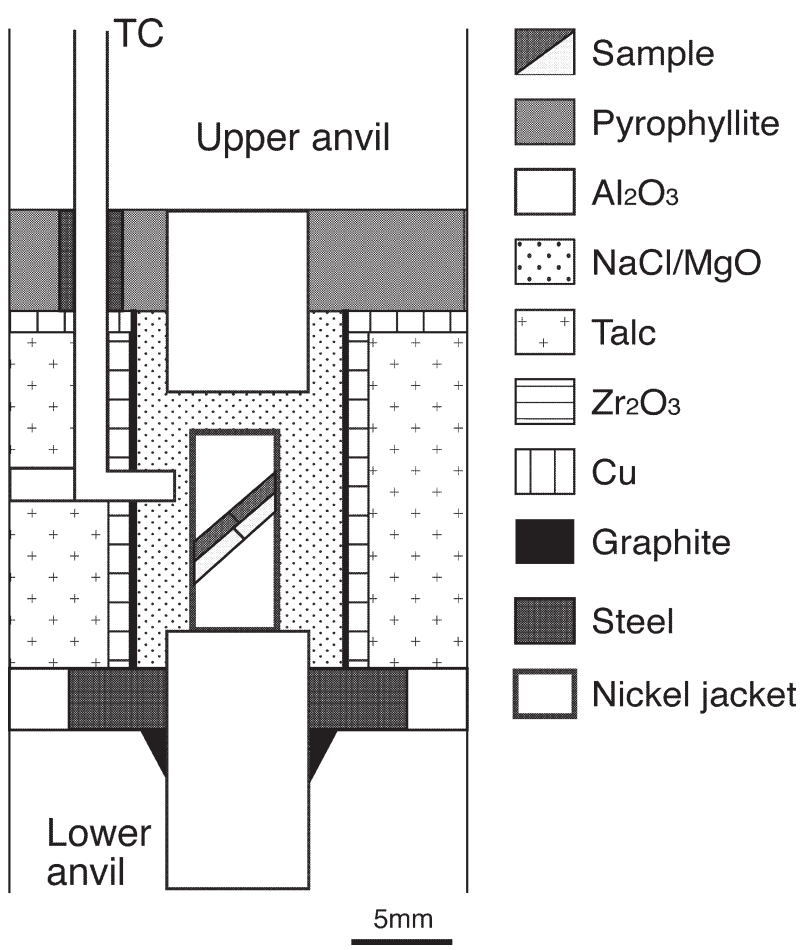

Figure 1. Experimental configuration of the two-layer shear deformation experiments. The olivine and plagioclase samples were sandwiched together between the alumina pistons, which are cut at $45^{\circ}$ from the maximum compression direction.

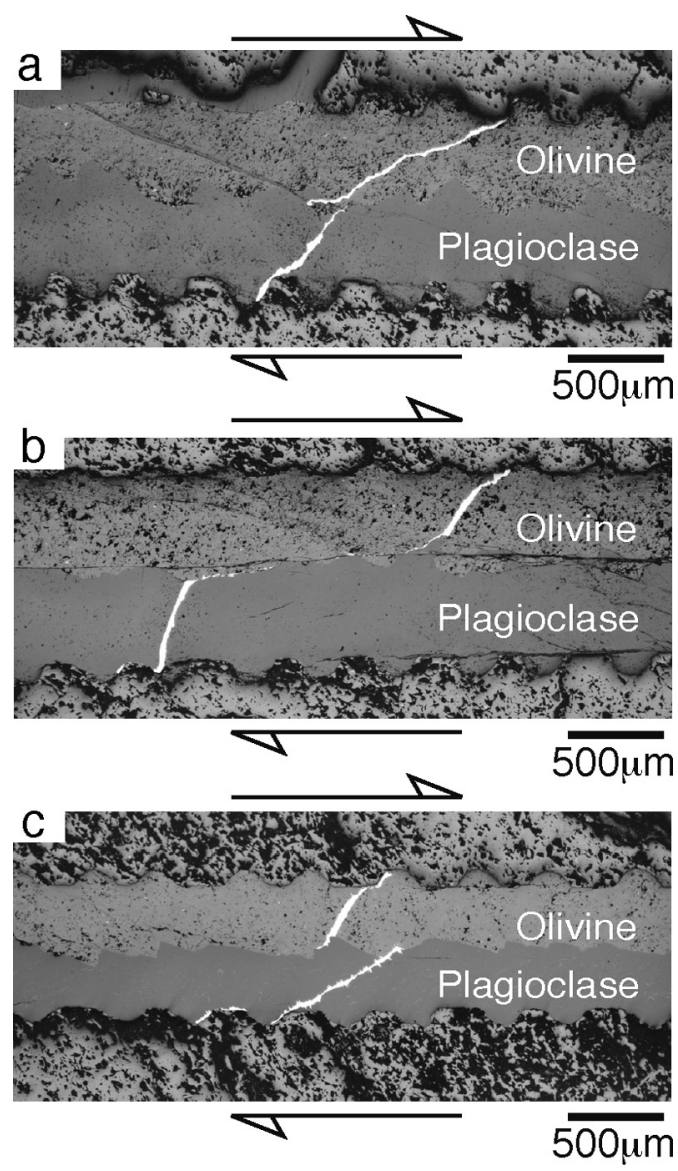

Figure 2. Microscope images of the deformed samples. The top and bottom arrows indicate a sense of shear. The nickel strainmarker (bright line in samples) was originally perpendicular to the sample plane, and the strain was estimated from the rotation of the strain-marker in each sample. (a) Recovered samples deformed at $P=1.0 \mathrm{GPa}$ and $T=400^{\circ} \mathrm{C}$, (b) at $P=1.0 \mathrm{GPa}$ and $T$ $=600^{\circ} \mathrm{C}$ and (c) at $P=1.0 \mathrm{GPa}$ and $T=800^{\circ} \mathrm{C}$.

pressure was then increased to $1.0 \mathrm{GPa}$ and temperature was increased to the desired value. Temperature was monitored by two $\mathrm{Pt} / \mathrm{Rh}$ thermocouples placed close to the sample. After the temperature was stabilized, a piston was advanced at a constant rate. The samples were rapidly quenched by switching off the thermo-controller when deformation experiments were finished. The shear strain was measured by the rotation of a Ni strain-marker in the recovered samples (Fig. 2), which was initially placed perpendicular to the shear direction. We also measured the compressional strain from the sample thickness before and after each experiment.

\section{EXPERIMENTAL RESULTS}

\section{Deformation microstructure}

The olivine and plagioclase samples were deformed to 
Table 1. Experimental conditions and results

\begin{tabular}{|c|c|c|c|c|c|c|c|}
\hline Sample no. & Starting material & $\mathrm{T}\left({ }^{\circ} \mathrm{C}\right)$ & $\begin{array}{l}\text { After experiments } \\
\text { grain-size }(\mu \mathrm{m})\end{array}$ & $\begin{array}{c}\text { After experiments } \\
\text { aspect ratio }\end{array}$ & Shear strain & $\begin{array}{c}\text { Strain-rate } \\
(/ \mathrm{s})\end{array}$ & $\gamma_{\mathrm{ol}} / \gamma_{\mathrm{pl}}$ \\
\hline \multirow{2}{*}{ Hi-301 } & Olivine & \multirow{2}{*}{400} & 16 & 1.8 & 3.2 & $3.5 \mathrm{E}-04$ & \multirow{2}{*}{4.9} \\
\hline & Plagioclase & & 14 & 1.5 & 0.7 & $7.2 \mathrm{E}-05$ & \\
\hline \multirow{2}{*}{$\mathrm{Hi}-307$} & Olivine & \multirow{2}{*}{400} & 16 & 1.5 & 1.9 & $2.2 \mathrm{E}-04$ & \multirow{2}{*}{2.0} \\
\hline & Plagioclase & & 15 & 1.4 & 1.0 & $1.1 \mathrm{E}-04$ & \\
\hline \multirow{2}{*}{$\mathrm{Hi}-300$} & Olivine & \multirow{2}{*}{600} & 19 & 1.6 & 0.7 & 7.3E-05 & \multirow{2}{*}{0.7} \\
\hline & Plagioclase & & 14 & 1.7 & 1.0 & $9.7 \mathrm{E}-05$ & \\
\hline \multirow{2}{*}{ Hi-309 } & Olivine & \multirow{2}{*}{600} & 19 & 1.5 & 1.2 & $1.2 \mathrm{E}-04$ & \multirow{2}{*}{1.0} \\
\hline & Plagioclase & & 16 & 1.5 & 1.2 & $1.2 \mathrm{E}-04$ & \\
\hline \multirow{2}{*}{ Hi-313 } & Olivine & \multirow{2}{*}{800} & 18 & 1.2 & 0.3 & $2.5 \mathrm{E}-05$ & \multirow{2}{*}{0.4} \\
\hline & Plagioclase & & 16 & 1.4 & 0.7 & $6.7 \mathrm{E}-05$ & \\
\hline \multirow{2}{*}{ Hi-315 } & Olivine & \multirow{2}{*}{800} & 17 & 1.4 & 0.6 & $7.4 \mathrm{E}-05$ & \multirow{2}{*}{0.4} \\
\hline & Plagioclase & & 15 & 1.8 & 1.8 & $2.1 \mathrm{E}-04$ & \\
\hline \multirow{2}{*}{$\mathrm{Hi}-316$} & Olivine & \multirow{2}{*}{800} & nd & nd & 0.8 & $9.6 \mathrm{E}-05$ & \multirow{2}{*}{0.5} \\
\hline & Plagioclase & & nd & nd & 1.6 & $1.9 \mathrm{E}-04$ & \\
\hline
\end{tabular}

All experiments were carried out at $P=1 \mathrm{GPa}$ and a constant piston displacement rate of $500 \mathrm{micron} / \mathrm{hour}$.

shear strains up to $\gamma=3.2$ and $\gamma=1.8$, respectively, in a nearly simple shear geometry (compressional strain is usually less than $20 \%$ of shear strain). After the experiments, we measured grain size of each sample by the in-

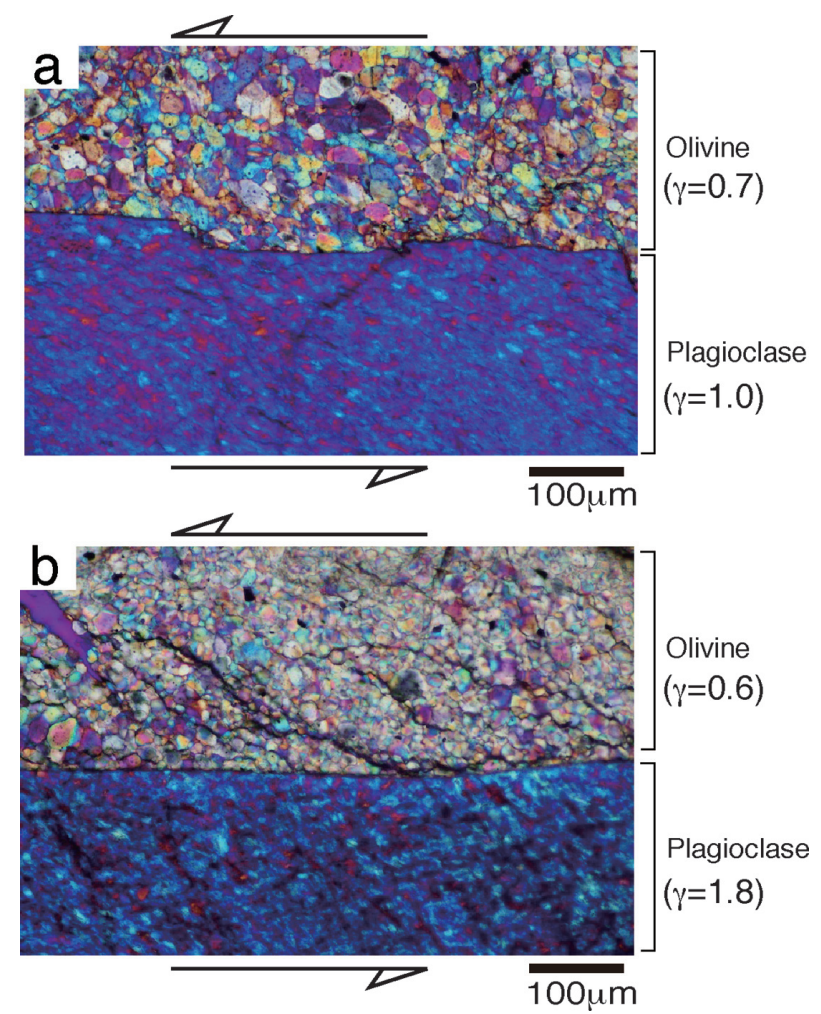

Figure 3. Microscope images of the deformed samples under a sensitive-tint plate. The top and bottom arrows indicate a sense of shear. (a) Recovered samples deformed at $P=1.0 \mathrm{GPa}$ and $T=$ $600^{\circ} \mathrm{C}$ and (b) at $P=1.0 \mathrm{GPa}$ and $T=800^{\circ} \mathrm{C}$. tercept method. The grain size of the recovered samples range from $\sim 17-19 \mu \mathrm{m}$ for olivine and $\sim 15 \mu \mathrm{m}$ for plagioclase (Table 1), which are similar to those of the starting materials. The grain boundaries are almost straight or smoothly curved in both deformed samples. The grain shape is nearly equant or slightly elongated for olivine, but plagioclase is significantly elongated subparallel to the strain-marker. Significant lattice-preferred orientation (LPO) was observed in plagioclase under a sensitive-tint plate (Figs. 3a and 3b), suggesting that deformation of plagioclase is predominated by dislocation creep. To determine the deformation mechanism of olivine, the dislocation density in olivine crystals was measured in the recovered samples. The samples are decorated by oxidation in air at $T=900{ }^{\circ} \mathrm{C}$ for $\sim 3$ hours and the oxidized dislocations were observed using a scanning electron microscope. Dislocation density of the deformed olivine sample (Hi-309) is $\sim 1.5 \times 10^{13} \mathrm{~m}^{-2}$, which is approximately one order of magnitude higher than that of starting material $\left(1.4 \times 10^{12} \mathrm{~m}^{-2}\right)$. The increase of dislocation density in olivine during deformation suggests intracrystalline deformation predominated via dislocation creep. In these experiments, we do not discuss stress, because dislocation density has a large uncertainty, resulting from the large number of dislocations.

\section{Results of mechanical test experiments}

The total strain rate is imposed by the velocity of the advancement of the piston, whereas the strain in each layer is determined only after each experiment. The uncertainty in the strain rate is estimated from the shape of the strain- 
marker, which is usually $10-20 \%$. Since the stress should be identical between the two layers, the contrast in strain provides an estimate of the contrast in strain rate at exactly the same stress, temperature, and pressure conditions.

The mechanical data in our experiments are summarized in Table 1 and plotted in Figure 4 as functions of strain-rate contrast between plagioclase and olivine and temperature. Our experimental results show that strain of olivine was greater than plagioclase at $T=400{ }^{\circ} \mathrm{C}$ (Fig. $2 \mathrm{a})$. However, as the temperature was raised, strain contrast between plagioclase and olivine becomes small (Fig. $2 \mathrm{~b}$ ), and strain of plagioclase is larger than that of olivine at $T=800^{\circ} \mathrm{C}$ (Fig. 2c). Consequently, strain contrast between plagioclase and olivine is sensitive to temperature, and plagioclase becomes weaker than olivine at the higher temperatures.

\section{DISCCUSION}

\section{Deformation mechanism}

Large extrapolation is needed in applying the laboratory data on plastic flow to geological processes and the extrapolation must be made using a flow law that is appropriate for the operating deformation mechanism under given conditions. The most commonly used flow law to analyze rheological data is the power-law formula of:

$$
\dot{\varepsilon}=A \sigma^{n} \exp \left(-\frac{E^{*}+P V^{*}}{R T}\right)
$$

where $\dot{\varepsilon}$ is the strain rate, $A$ is a constant, $\sigma$ is the stress, $n$ is the stress exponent, $E^{*}$ and $V^{*}$ are the activation energy and volume, $R$ is the gas constant, and $P$ and $T$ are the pressure and temperature (e.g., Poirier, 1985). This relation indicates that the strain rate is proportional to the power of the applied stress, and temperature and pressure effects are represented by the activation energy and volume, respectively. Extrapolation of the power-law relations to our deformation conditions indicate that olivine is always stronger than plagioclase and the difference in strength between these materials becomes larger with decreasing temperature because activation energy of plagioclase is larger than that of olivine (Karato and Jung, 2003; Rybacki et al., 2006). However, our experiments show that strength (strain) contrast changes with temperature, and olivine becomes weaker than plagioclase at temperatures below $600{ }^{\circ} \mathrm{C}$ (Fig. 4). This implies that the powerlaw relation may not be an appropriate mechanism for our experimental data.

In materials with a relatively strong chemical bonding such as silicates, Peierls mechanism becomes domi- nant at low temperatures (e.g., Tsenn and Carter, 1987), in which strain-rate is exponentially proportional to applied stress as

$$
\dot{\varepsilon}=A \sigma^{2} \exp \left[-\frac{E^{*}+P V^{*}}{R T}\left\{1-\left(\frac{\sigma}{\sigma_{P}}\right)^{p}\right\}^{q}\right]
$$

where $\sigma_{\mathrm{p}}$ is the Peierls stress, and $p, q$ are non-dimensional parameters that depend on the geometry of kinks (e.g., Kocks et al., 1975). Based on deformation mechanism map, deformation of olivine could be controlled by this type of flow mechanism under our low temperature experiments, whereas mechanism for plagioclase is not well constrained. Tsenn and Carter (1987) proposed that power-law break down occur at $10^{-2} \mu(\sim 400 \mathrm{MPa})$, suggesting that plagioclase can also be deformed via Peierls mechanism. Thereby, the strength contrast was caused by difference in Peierls stress between olivine and plagioclase. Our experimental results are different from that extrapolated from the power-law relations and the strength contrast between plagioclase and olivine are reversed at low temperatures.

\section{Strength contrast at Moho depths}

The strength profile has been inferred from extrapolating frictional behavior and viscous flow law of each material at high pressure and temperature corresponding to the Moho depths (Burgmann and Dresen, 2008). In the previous studies, the power-law relation has been applied to the Moho conditions; however, our experiments showed that the power-law is not appropriate at low temperatures and Peierls mechanism might be used in those environ-

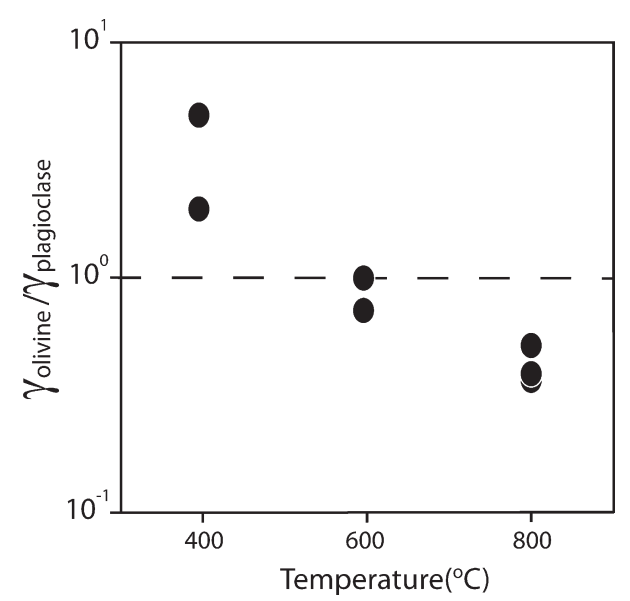

Figure 4. Temperature and strain contrast relation between the plagioclase and olivine at $P=1.0 \mathrm{GPa}, T=400-800{ }^{\circ} \mathrm{C}$ under water-rich conditions. Plagioclase is stronger than olivine at lowtemperatures, but plagioclase is weaker than olivine at relatively higher temperatures. 
ments. We performed experiments directly determining strength contrast between the lower crust (plagioclase) and upper mantle (olivine) under the wet Moho conditions, and found that olivine is expected to be weaker than plagioclase or show almost no difference in strength at temperatures of the continental Moho, $\sim 500-600^{\circ} \mathrm{C}$ (Fig. 4). Plagioclase is generally believed to be weaker than olivine (Brace and Kohlstedt 1980), however some natural observations, such as boudin structure of plagioclase in olivine matrix from the Oman ophiolite (T. Hiraga, personal communication, 2010), suggest that the strength contrast between plagioclase and olivine might be reversed under different geological conditions. This observation agrees with our results, and the strength crossover may occur in natural conditions. These experimental results are consistent with the "crème brulee" model, in which the upper mantle below the Moho is expected to be comparable or less viscous than crustal materials (e.g., Burov and Watts, 2006). Jackson (2002) has suggested that the strength of continental lithosphere resides entirely in the crust and the upper mantle is significantly weaker owing to temperature and weakening resulting from high water contents. In the "crème brulee" model, the strength in the continental lithosphere resides almost in the crustal layer and seismogenic layer would be limited by crustal depths. Indeed, earthquakes are very rare in the continental upper mantle and their distribution corresponds to the lowermost part of the continental crust (Watts and Burov, 2003). In this study, we discussed the strength contrast at the Moho depths under water rich conditions. However this result may not be appropriated under dry environments. Thus, future experiments evaluating the effect of water to extrapolate the strength contrast under dry Moho conditions are required.

\section{ACKNOWLEDGMENTS}

We thank Jun-ichi Ando for experimental assistance. Comments by Eiji Ohtani, Tomoaki Kubo and anonymous reviewer were helpful to improve the manuscript. We also appreciate Frances Jenner for English correction in the text. This study was supported in part by the Grant (No.
19740329) from JSPS to I. Katayama.

\section{REFERENCES}

Brace, W.F. and Kohlstedt, D. (1980) Limits on lithospheric stress imposed by laboratory measurements. Journal of Geophysical Research, 85, 6248-6252.

Burgmann, R. and Dresen, G. (2008) Rheology of the Lower Crust and Upper Mantle: Evidence from Rock Mechanics, Geodesy, and Field Observations. Annual Review of Earth and Planetary Sciences, 36, 531-567.

Burov, E.B. and Watts, A.B. (2006) The long-term strength of continental lithosphere: "jelly sandwich" or "creme brulee"? GSA Today, 12, 4-10.

Chen, W-P. and Molnar, P. (1983) Focal depths of intra- continental and intraplate earthquakes and their implications for the thermal and mechanical properties of the lithosphere. Journal of Geophysical Research, 88, 4183-4214.

Jackson, J. (2002) Strength of the continental lithosphere: time to abandon the jelly sandwich? GSA Today, 12, 4-9.

Karato, S. and Jung, H. (2003) Effects of pressure on high-temperature dislocation creep in olivine. Philosophical Magazine, 83, 401-414.

Kocks, U.F., Argon, A.S. and Ashby, M.F. (1975) Thermodynamics and kinetics of slip. Progress in Material Science, 19, 1-291.

Kohlstedt, D.L., Evans, B. and Mackwell, S.J. (1995) Strength of the lithosphere: Constraints imposed by laboratory experiments. Journal of Geophysical Research, 100, B9, 1758717602.

Kohlstedt, D.L., Keppler, H. and Rubie, D.C. (1996) Solubility of water in the $\alpha, \beta$ and $\gamma$ phases of $(\mathrm{Mg} \mathrm{Fe})_{2} \mathrm{SiO}_{4}$. Contributions to Mineralogy and Petrology, 123, 345-357.

Poirier, J.P. (1985) Creep of Crystals. pp. 260, Cambridge University Press, New York.

Rybacki, E., Gottschalk, M., Wirth, R. and Dresen, G. (2006) Influence of water fugacity and activation volume on the flow properties of fine-grained anorthite aggregates. Journal of Geophysical Research, 111, B03203.

Tsenn, M.C. and Carter, N.L. (1987) Upper limits of power-law creep of rocks. Tectonophysics, 136, 1-26.

Watts, A.B. and Burov, E.B. (2003) Lithospheric strength and its relationship to the elastic and seismogenic layer thickness. Earth and Planetary Science Letters, 213, 113-131.

Manuscript received June 18, 2010

Manuscript accepted August 18, 2010

Published online October 13, 2010

Manuscript handled by Eiji Ohtani 